\title{
中美地摊文化之差异
}

\section{Differences between Chinese and American Stall Culture}

\author{
丁清清 \\ Qingqing Ding \\ 九江学院外语学院 江西 九江 332005
}

School of Foreign Language Jiujiang University Jiujiang Jiangxi 332005

摘 要: 本文主要对中美两国地推的不同种类、经济特点、形成背景进行对比, 从而使读者能从地推文化的角度探知中美文 化的差异。

\begin{abstract}
This paper mainly compares the different types, economic characteristics and formation background of stalls between China and the United States, so that readers can find out the cultural differences between them from the perspective of stall culture.

关键词:地摊文化; 差异;地摊
\end{abstract}

Keywords : stall cultural; differences; street stall

DOI : $10.36012 / \mathrm{emr} . v 2 \mathrm{i} 6.2987$

地摊作为人类社会生活不可或缺的一部分, 是居民生活 充满烟火气息的重要元素。中美城市都有大大小小的地摊, 它们随时代而发展, 成为城市的重要组成部分。无论是商业 区还是居民区，各式各样的摊贩都在尽职尽责地丰富和便利 着人们的生活,激发着城市的活力。地摊在繁荣的同时,地摊 文化也逐渐形成、适应并发展。中美两国在地理、政治、经济 基础方面大相径庭,形成的地摊文化也不尽相同。

\section{1.地摊文化的概念和特点}

地摊文化一般指在地摊及其衍生品下所生成的一种文 化。随着全球经济高速发展, 人们的物质生活日渐丰富,整齐 划一的商店和超市出售的统一规格的产品不再能满足人们 多样化的需求了,地摊这种创意市集迎合了时代的发展并因 其在运作过程中展现的创意、时尚、潮流等新优势, 地摊文化 走向欣欣向荣。

地摊文化的特点: 1$)$ 时效性: 地摊文化是一种与时代密 切相关的文化,与同期的人们生活习性直接相关联。2) 区域 性: 根据地理位置和饮食习惯不同, 每个地区的地摊出售物 品会有所不同。3) 多样性: 每个购物者的需求不尽相同、出售 的物品也千差万别, 这就势必形成了地摊文化的多样性。

\section{2.地摊文化的主体: 地摊}

\section{1 中国地摊的种类：}

2.1.1 地摊吼货。所谓的吼货就是以做特价、大喇叭叫卖 等促销商品, 达到营销目的, 尤其在农贸市场和乡镇盛行。

2.1.2 地推推广货。推广货的一个卖点就是宣传、炒作 产品的功能, 简单来说就是将产品的功能夸大。

2.1.3 固定摊贩。固定摊贩出售货就是指在固定摊位销 售的货物。一般是在农贸市场里面, 其商品摆放相对整齐, 经营模式较有规律性,以卖讲价货为主。

2.1.4 流动摊贩。流动摊贩主要以卖吼货为主, 兼卖讲 价货, 他们活动在一个城市里面, 每天不固定在一个地方, 流 动售卖。

2.1.5 商品展销会(赶会)。乡县每年都会举办展销会, 俗 称赶会。一般由政府主办, 然后承包给个人。赶会期间生意火 爆, 大部分摊子上都是价格便宜且质量差的商品。

\section{2 美国地摊的种类}

2.1.1 旧货市场(Second-hand Market)。旧货市场也称跳 蚤市场 (flea market), 市场规模大小不等, 产品种类多样, 有 汇聚各国独特风味餐厅、食吧, 如遇特定节日, 还会举办各种 活动回馈新老顾客。

2.1.2 农夫市场(Farmers Market)。农夫市场类似中国的农 贸市场, 出售各种蔬菜、肉类(海鲜类较少)为主, 兼售一些食

【基金项目】该论文是九江学院外语学院 2017 届学生丁清清的毕业论文中文翻译, 其指导老师为喻泪波。

【作者简介】丁清清(1999 ),女,江西抚州人,汉族, 本科, 研究方向: 中美文化。 
物成品。不同的是这种市场是由政府组织主办的。农夫市场 的举办通常会被指定地点、日期。

2.1.3 草坪市场 (Yard Sale) 或车库出售 (Garage Sale)。车 库出售也称为庭院旧货出售, 售卖的货物是家庭中不需要且 可再次利用的物品。

2.1.4 艺术家集市 (Artists \& Fleas)。位于威廉斯堡的艺 术家集市 (Artists \& Fleas) 有众多艺术匠创作的创意手作, 这 些手作材质上不追求高价值, 手作服饰设计感强, 制作技术 较高, 潮人范儿十足, 深受青年人喜欢。将古董与艺术融合是 艺术家集市的特色之一。

\section{3 地摊经济的特点不同}

“地摊经济”在中国拥有“三低”特质:一、创业门槛低: 无 需店铺租金, 投入少, 无学历与技能要求; 二、投资风险低: “船小好调头”就是它的真实写照; 三, 价格较低: 能够让居民 拥有更多选择, 享受更多便利和实惠。

美国地摊经济特质如下: 一, 摊贩老板会宣扬商品的内 在价值而并非一味以价格低吸引人。二, 多数摊贩数量和地 点经过科学规划, 不能影响当地交通和周围民众的生活, 也 要照顾到有足够的往来客流量。三, 摆摊要申请资格,即持证 上岗, 有相关部门在管理地摊, 这要求商贩交税, 大大加大了 摆地摊的成本门槛。

\section{3.中美地摊优缺点异同}

\section{1 对社会积极作用}

3.1.1一定程度上缓解了就业压力。地摊运营成本少, 就 业门槛低、失败风险低、行业和门类广、包容性强, 创造就业 岗位, 缓解就业压力, 对于维系经济社会稳定, 对社会发展具 有积极作用。

3.1.2 满足了低收入阶层的消费需求。地摊商品无需支 付店铺租金、缴税等其他额外费用, 价格相对较低, 正好满足 了低收入阶层的需求。

3.1.3 丰富了城市的文化结构。地摊能够营造一种城市 街头文化氛围。摊点上摆放的物品常能体现当地的风土人 情, 也给市民休闲娱乐提供了去处: 如中国街头黄梅戏, 美国 街头摇滚音乐,丰富了大众生活。

\section{2 存在的问题}

3.2 .1 影响市容, 容易造成环境污染。根据艾媒数据中心 关于消费地点分布数据显示, 住宅区是地摊消费的主要场
所, 占比为 $56.21 \%$; 其次是商业区, 步行街、商圈附近分别为 $42.48 \%$ 和 $30.72 \%$, 这些摊点随意摆设, 使原本狭窄的道路更 加拥堵, 给居民带来巨大不便, 也影响到城市的整体市容。

3.2 .2 给城市社会治安增加了难度。中国地摊经营相关 法规不完善,造成地摊管理难。美国地摊经营场所, 客流量 大, 人员庞杂, 闲散人员聚集,偷窃事件时有发生; 有些街道 表面做着买卖实则做着毒品交易, 其冲突引发枪击事件屡见 不鲜。

3.2 .3 损害消费者利益。地摊上售卖的物品多为低档廉 价商品, 其中不乏假冒伪劣, 产品质量难保障, 产品售后服务 也得不到监管, 一些商贩为了眼前利益而欺骗消费者, 经常 缺厅少两,以次充好。

\section{4.中美街头文化的差异}

高空翻梯、胸口碎大石、说相声、数来宝、凤阳花鼓、吹糖 人儿都是中国街头文化, 这些市民文化贴近民众生活, 为人 民大众所喜闻乐见。

在美国街头,乐器演奏、杂技、魔术、涂鸦等街头艺术向 更广泛的公众解释街头艺术的真实本质,除此之外还有静态 的人体雕塑, 动态的歌舞技巧,精湛的器乐演奏, 现场的写真 画像等,这些街头艺术的表演者,成为赏心悦目的都市景观。

\section{5.中美地摊文化形成背景差异}

\section{1 文化的包容性}

美国文化容纳了各国文化精华，具有宽容兼纳的一面， 街头古老与现代同在,传统与时髦并存。中国文化海纳百川, 将国内各个地区的文化特色相互融合, 推陈出新。

\section{2 现实需要}

美国商品更新换代速度快,旧货需要被淘汰, 售卖可以 节省一些成本。另一种是市场刚需原因, 人人对于提供日常 便利的地摊有着刚性需求。

中国企业受新冠影响，社会消费品零售总额下降 $16.2 \%$, 其中中小微企业和个体商户面临着空前风险, 这时小 巧便利的地摊便趁势而上,带给城市生机。

\section{3 价值观的体现}

为让闲置的物品物尽其用，美国民众会在自家门前摆 摊, 廉价出售或半卖半送给需要的人,这种交易传承了节约 理念, 很多美国家庭会用卖旧货教育孩子,让孩子体会到赚 
战略性人才资源的开发, 如关键技术创新团队、中高层管理 团队的塑造培养, 提高民营企业的人力资源优势。建设一个 民主集中,平等互利的企业文化，建立健全的激励制度。从根 本上保证激励制度的公平性, 对待员工不唯亲, 不避疏, 按照 员工的能力和业绩来分配其工资。各种福利制度与保险制度 的建立, 为员工解决了后顾之忧, 使他们能够全身心的投入 到工作中去, 充分发挥自己的知识才智, 为企业谋利益。

\section{3 提高企业的自主创新能力, 建立适应新形势的 商业经营模式}

措手不及的疫情让很多中小企业开始反思自己存在的 意义和价值。疫情之下, 消费者的消费心理在快速变化, 竞争 对手的情况也较之以往发生了很大的变化。拥有正确的战略 才能保障企业在疫情阴霧笼罩之下,实现自我拯救。疫情期 间一批生鲜电商迎来了爆发式增长, 更出现了企业家直播带 货的现象,为特殊时期的消费模式注人了新动能。企业战略 要以市场为基准,动态地去判断消费者和竞争对手的变化,找
准自己的市场地位,并匹配和自身战略相适应的战术。

\section{4 营造公平竞争环境,保护企业家人身财产安全}

进一步放开民营企业市场准入, 精简市场准入行政审批 事项,保障民企与国企平等地位。在政府采购、工程建设项目 招标等事项中, 破除招投标隐性壁垒。加强公共服务体系建 设,运用市场运作模式,通过政府购买服务等方式, 为广大民 营企业提供精准化、专业化服务。建立健全保护民营企业物 权、债权、股权、知识产权等各类产权的法规制度，依法保护 民营企业特别是中小企业及其出资人的财产权和其他合法 权益。

\section{参考文献}

[1] 陈斯,蔡哲.民营企业发展面对的困难及对策.企业战略.2016, (8).

[2] 倪䈗楠,侯聪聪.新冠肺炎疫情前后民企融资的“难”与“易”.投 资与融资.2020,(6)

[3] 刘伟,苏剑. 疫情冲击下的 2020 中国经济形势与政策选择.社会 科学研究.2020,(5)

\section{(上接第 4 页)}

钱的不易,这体现了美国个人主义价值观。但中国人喜欢热 闹的氛围,地摊本身恰好具有的人间烟火气,体现中国集体 主义。

\section{6. 总结}

中美地摊文化的形成建立在本国底层群众的需要之上, 透过中美地摊文化差异能够看出中美两国文化差异, 地推文 化反映中美社会状况, 价值理念的不同, 利于更好进行中美 跨文化交流。

\section{参考文献}

[1] Review of "Yardsale" by Matthew Sorrento,Au gust 22, 2006

[2]"Robert A.Emmons' website".Robertemmons .com

[3] 宫业竹. 青岛地摊经济发展现状及管理对策研究--以李村地摊 经济为例[D]中国海洋大学, 2011

[4] 刘再生. 走下神坛的音乐--《街头音乐--美国社会和文化的一 个缩影》读后感 $[J]$.人民音乐,2002(07):48-49.

[5] iMediaResearch(艾媒咨询)《2020H1 中国地摊经济运行监测 分析报告》,艾媒产业升级研究中心艾媒网,2020-06-12 Retrieved 2012-06-09.

\section{(上接第 65 页)}

\section{5. 总结}

健康管理企业经侦的核心是价值而不是价格, 促进健康 管理行业不断发展的动力是服务,企业服务营销优化策略是 整个行业经济发展的需要。我们只有首先理清健康管理企业 服务营销的相关发展理念, 并且认识到企业营销过程中实际 存在的种种问题并加以针对性地解决, 才能够做到健康管理 企业服务营销策略的不断优化，从而促进整个行业的可持续
性健康发展, 为服务行业经济发展贡献微薄之力。

\section{参考文献}

[1] 基于家庭医生服务平台的企业管理和技术人员健康管理效果 评估[J].王书军,陈黎.上海医药.2018(08)

[2] 关于健康管理未来发展的可行性分析[J].杜佳芯, 于晓䜀, 王金 榕.广西质量监督导报. $2020(01)$

[3] 基于岗位胜任力的市场需求健康管理专业人才培养方案研究 [J].王大红, 黑启明.教育现代化.2019(A0) 